\title{
Las Mercedes y las Acequias
}

\author{
Juan Estevan Arellanoํㅜ José A. Rivera², and Enrique R. Lamadrid ${ }^{1}$ \\ ${ }^{1}$ Acequia Junta y Ciénaga, Embudo, NM, USA, ${ }^{2}$ University of New Mexico, Albuquerque, NM, USA \\ estevanarellano@gmail.com, jirivera@unm.edu, lamadrid@unm.edu,
}

\begin{abstract}
Resumen. Para comprender mejor las acequias del Embudo de Picurís se tienen que analizar como componente vital de las mercedes de tierras otorgadas a los pobladores por la Corona española. Muchos investigadores han estudiado las acequias únicamente como el canal que lleva agua, sin ver que las acequias son una parte íntegra de todo el paisaje, empezando en la sierra y terminando en el río. Son parte de la cuenca, que si se le hace daño a esta parte del paisaje, afecta a las acequias que corren más abajo. Cuando se examina el paisaje de la merced se ve que la acequia es como una faja que divide las tierras comunales de las tierras privadas y de regadío. Las tierras comunes de las mercedes, conocidas en Nuevo México como los ejidos son compuestas de las sierras, montes, dehesas o llanos y los solares donde la gente levanta sus casas donde van también las dispensas, trochiles, gallineros y la leña. Luego corre la acequia que riega las tierras más productivos que son los altitos donde se establecen los huertos de árboles frutales, las jollas donde se siembran las milpas y las huertas, las vegas donde también se puede sembrar pero se usan más para los animales de casa y las ciénagas (aquí también van los prados y los potreros). Luego cerca al río están los bosques donde existen los esteros y resumideros.
\end{abstract}

Palabras clave: Merced, acequia, cuenca, irrigación.

\begin{abstract}
To better understand the acequias in "Embudo de Picuris," they have to be analyized from the perspective of the land grants given to the settlers by the Crown of Spain. Many scholars have studied the acequias simply as canals that transport water, without realizing they are an integral part of the landscape, starting with the sierra and ending at the river. They are part of the watershed, that if the landscape is damaged, this will affect how the lower acequias flow. When one looks at the landscape one sees that the acequia is like a belt that separates the commons from the irrigated land. The common lands in the land grants, known in New Mexico as ejidos are made up of sierras, mountains, commons and lots where people build their houses, plazas, and also the utility rooms, pig pens, chicken coops and wood pile. Then runs the acequia that irrigates the most productive pieces of land that are known as altitos where the orchard trees are planted, the jolla where the corn fields and chile are planted, the vegas that can also be used to grow food but they are used more for the domestic animals, and the cienagas or marshlands (including the prados and potreros). Then close to the river are the bosques where one finds the estuaries and quicksand.
\end{abstract}

Key words: Land Grant, acequia, watershed, irrigation

\section{Introducción}

La entidad más antigua en el Nuevo México moderno son las acequias que fueron introducidas en 1598 por los primeros colonos bajo la Corona española en lo que hoy día es el valle de la Española. Bajo la dirección de don Juan de Oñate, llegaron a Ohkay Owingeh el día 11 de julio de 1598, cuyo nombre se cambió a San Juan de los Caballeros. Dentro de un mes de llegar empezaron a sacar la acequia más vieja en la presente aldea de Chamita en la junta del río Chama y río del Norte, conocido hoy día como el río Grande.

Después de la Rebelión de los pueblos en el 1680, y después de la llamada reconquista bajo don Diego de Vargas, para poblar la provincia de la Nueva México, la Corona empezó a dar mercedes de tierra (y unas cuantas de agua) a la gente militar para poder establecer una presencia de nuevo en esta tierra septentrional. 
Para clarificar, las mercedes dadas por la Corona española empezando a principios del siglo 18 eran diferentes a las mercedes dadas bajo el gobierno de México entre 1821 y 1848. El dos de febrero del 1848, se firmó el tratado de Guadalupe Hidalgo en que México cedió estos territorios del norte a los Estados Unidos. La diferencia era que el tamaño de los terrenos de las mercedes españolas eran más medianas que las mexicanas, que eran más como estancias. Importantes para este análisis son cuatro textos históricos, 1) Las Siete Partidas de Rey Alfonso el Sabio del 1256, 2) las Ordenanzas de Descubrimiento, Nueva Población y Pacificación de las Indias, dadas por Felipe II en 1573, 3) la Recopilación de las Leyes de los Reynos de Indias en el 1681 y 4) el Plan de Pitic del 1783.

Yo me dediqué a estudiar estos textos después de la rebelión de la Alianza de Pueblos Libres, el movimiento para recuperar las mercedes que encabezó Reis López Tijerina. Así traté de comprender lo que pasó el 5 de junio del 1967, cuando él y sus "valientes" armados trataron de arrestar al Fiscal del estado, un incidente que capturó la atención del mundo entero. Mi papá siempre mencionaba las mercedes, especialmente cuando íbamos a visitar a una tía que se llamaba Merced. Él siempre decía, "todas estas tierras eran de la merced y yo como estaba niño, pensaba entre sí, 'mi tía Merce quizás tenía mucha tierra'. Hasta después del episodio este que pasó en Tierra Amarilla no comprendí la diferencia y desde entonces me puse a estudiar las mercedes dentro del contexto de los textos mencionados arriba.

\section{La Cuenca del Embudo}

Para este trabajo me voy a concentrar más en una merced dentro de una cuenca tributaria del río Grande, la merced del embudo de Picurís dentro de la cuenca del mismo nombre. La cuenca del Embudo es mediana de $516 \mathrm{~km}^{2}$ y empieza en el sur de las Montañas Rocosas como a cuarenta millas de la capital de Nuevo México, Santa Fe. La sierra principal de la cuenca del Embudo viene siendo nuestra madre la Jicarita, una gran montaña pelada que es semejante a una jícara volteada bocabajo. Se estira al sur hasta el pico de Truchas, el segundo más alto en Nuevo México de 13,108 pies. El dicho pico divide las cuencas del río Grande del río Pecos. Al poniente corre el río Medio, río Quemado y el río Trampas y al noreste el río Santa Bárbara. Desde al norte hasta lo que se conoce como el cañón de la junta y termina como cuarenta millas al poniente donde el río Embudo se desemboca al río Grande. De ahí agarrará la cuenca su nombre de embudo, siendo que tiene la forma de un triángulo, o también parece la forma de un hombre en cruz con la Jicarita representando la cabeza con sus brazos extendidos hasta el pico Truchas hacia el sur y el cañón de la Junta hacia el norte, y los pies donde los dos ríos se juntan, que la gente local llama la "Junta de los Ríos." Esta cuenca tiene varios tipos de zonas ecológicas, desde la más alta la zona alpina, a la zona del pino real y abeto, a la zona del pinabete, hasta llegar a la zona del piñón, sabina y varias clases de chamiso.

\subsection{Zonas dentro de la Cuenca}

2.1.1 Zona alpina. La cordillera que empieza en el cañón de la Junta, pasa por la parte pelona de la Jicarita y se extiende hasta el pico Truchas; todo lo que está arriba de 10,000 pies se considera una zona alpina. Esta zona tiene algo de problemas con la erosión en las partes donde está pelada por la nieve y agua siendo que las plantas crecen aquí muy despacio. La zona esta es lo que recibe la mayoría de la nieve durante el invierno, a veces nieva hasta los últimos de mayo y ha nevado lo más tarde el día de San Juan, el 24 de junio. 
Esta zona también recibe la más cantidad de agua, como 40 pulgadas de agua al año, y en realidad viene siendo la hielera, o el banco para nuestra agua y lo que da vida a las acequias.

2.1.2 Zona de Pino Real y Abeto. En esta zona no existen habitantes humanos, solo en el verano cuando llegan tanto locales como turistas a recrear por días y a veces algunos se quedan por toda la temporada del verano. Erosión no es problema aquí; esta área es lo que se conoces como el Pecos Wilderness, abajo en la Jicarita, la mayoría del cañón de la Junta. Esta zona recibe como 30 pulgadas de agua por año y también bastante nieve. Sus cañones hondos también sirven para guardar la nieve que empezando en mayo surte a las acequias.

2.1.3 Zona de Pinabete. En esta zona están las comunidades de Ojo Sarco, El Valle, Llano de San Juan, Llano de la Yegua, Rodarte, Peñasco y alcanza hacia el rumbo de la sierra hasta Tres Ritos. El terreno es uno de colinas y cuestas escarpadas. Las condiciones a lo largo del lindero oriente están satisfactorias. Lo demás del área está cubierta pobremente por plantas y tiene erosión severa. Hay muchas áreas que son privadas, perteneciendo a los descendientes de algunas mercedes de la alta cuenca del Embudo y las demás le pertenecen al gobierno federal, manejadas por la agencia del "National Forest Service" el servicio forestal federal. El área de Peñasco y el Llano reciben como de dieciséis a veinte pulgadas de agua y el área de Tres Ritos como veinte y cinco pulgadas de lluvia por año. Aquí está la merced de Santa Bárbara, Vigil, Trampas y parte de la Sebastián Martín; también incluye la merced indígena de Picurís.

2.1.4 Zona de Piñón, Sabina y Chamiso. Esta zona es caracterizada por cuestas escarpadas, mesas y arroyos hondos, cañones y cañadas y colinas y se extiende desde el río Pueblo, río Santa Bárbara, y río Embudo entre las alturas de 5,800 a 7,500 pies. El suelo es de tierras de aluvión de fondo antiguo con buena fertilidad, aunque la erosión es una gran preocupación, especialmente en las colinas de pie en las comunidades altas en el río Santa Bárbara, el río Trampas, Chamisal y el bajo Embudo en Cañoncito, Montecito, Apodaca, Bosque, Dixon, Embudo y Rinconada, aunque esta aldea está al bordo del río Grande. Aquí hace mucho tiempo que no se pastean animales en los ejidos. Los vehículos fuera de caminos han dejado cicatrices hondas en las colinas frágiles por todo el valle y los arroyos se han vuelto monstruosidades llenos de basura donde se deposita la basura casera. El valle bajo del Embudo, donde está situada la merced de Embudo, recibe como doce pulgas de agua por año, mientras las Trampas y el Ojo Sarco como catorce pulgadas. Para este trabajo la zona que nos interesa más es la de piñón, sabina y chamiso, que es el tipo de tierra en al merced del Embudo que ocupa un triángulo al poniente de la cuenca del Embudo.

\section{Ejidos; tierras comunales}

Un ejido, según Covarrubias, viene siendo "el campo que está a la salida del lugar, el cual no se planta ni se labra, porque es de común para adorno del lugar y desenfado de los vecinos de él y para descargar sus mieses y hacer sus parvas." Viene del latine exitus, de exeo, $i s$, por salir. La salida de un lugar, como cuando se vende un lugar "con entradas, e con exidas," que vale (o equivale) salidas. El diccionario de la Real Academia dice que es un "campo común de un pueblo, lindante con él, que no se labra, y donde suelen reunirse los ganados o establecerse las eras." Cuando se habla de mercedes, los ejidos son los que se perdieron cuando el gobierno americano tomó posesión de las tierras dadas tanto por la Corona de España tanto como las mercedes hechas por el gobierno de México. La lucha 
siempre ha sido por estas tierras, siendo que por la mayor parte las suertes todavía están bajo control de individuos igual que las acequias aunque a veces ellas empiezan en propiedad reclamada por la floresta (National Forest Service) o el Bureau of Land Management. Hasta el día todavía existen peleas entre la gente y las agencias gubernamentales, aunque las acequias han existido por cientos de años antes.

Las tierras comunales de las mercedes son las tierras que están situadas arriba de las acequias, que son las sierras, montes y llanos o dehesas. En muchos casos también incluyen los solares donde se edifican las casas y también las plazas o plazuelas. Aunque no se riegan, alguna gente siembra en las dehesas al temporal, en el secano.

\subsection{Sierras}

Las sierras son las tierras en la zona alpina, y es donde se guarda la nieve que durante el verano provee el agua para las acequias para regar las suertes donde se siembran las hortalizas. La palabra sierra se le "llama la tierra montañosa y desigual, con sus peñascos resquebrajados semejante a los dientes de la sierra instrumento," escribe Covarrubias. El padre Guadix dice es nombre arábigo. "De instrumento para dividir la Madera, por sus dientes agudos." Vienen siendo parte de una cordillera de montes o peñascos cortados. Una cordillera viene siendo, entonces, el lomo que hace alguna tierra, seguido e igual, que parece ir a cordel, o una serie de montañas enlazadas entre sí.

\subsection{Montes}

Los montes (del lat. mons, montis), gran elevación natural de terreno, tierra inculta cubierta de árboles, arbustos o matas; ubicados en la zona de pinorreal y abeto, y a veces también incluye piñón y sabina. Dice Covarrubias, "Monte viene del Latín mons o montis, tierra alta, mientras montaña es tierra alta, áspera y habitata," y cita un enigma sobre montañas que reza,

\section{Preñado dicen que estoy \\ Y jamás a parir vengo, \\ Lomos y cabeza tengo \\ $Y$ aunque vestido no estoy \\ Muy grandes faldas mantengo.}

Las montañas se dice que están preñadas por sus grandes rumores e hinchazones, pero nunca paren y tienen también cabeza, cima y espaldas y sus vertientes llamamos faldas aunque no anden vestidos. Y dicen comúnmente que los montes tienen faldas. A las montañas también se les dice tener cejas, que viene siendo la parte superior o cumbre del monte o sierra. En los montes y montañas existen las llamadas cuchillas, que se asemejan a una cuchilla y también cordilleras como en las sierras.

\subsection{Dehesas, los llanos}

Esta zona tiene más piñón, sabina y también diferentes tipos de chamiso. En los llanos, los más cerca de las casas, a veces se siembra frijol pinto o frijol de bolita, siendo que no ocupa mucha agua. El frijol se da mejor en secano que donde se riega mucho; si recibe mucha agua se hace duro cuando se cocina. Este tipo de agricultura se conocía como tierras de pan llevar, de secano o temporales, indicando se sembraba cuando ya estaban las lluvias para llegar. 
Las tierras no de regadío, conocidas como tierras de secano, están en lo más bajo de las dehesas, conocidas también como tierras de pasto. En latín dehesa se dice pascua, y es un lugar para pastear el ganado. El término pudiera haber venido de la costumbre. La palabra dehesa aparece por primera vez en Corominas en el año 924 aunque los romanos notan que aparece en las leyes de los visigodos. Según Covarrubias "dehesa" es un campo de yerba donde se apacienta el ganado. Según Diego de Urrea es un nombre arábigo que significa tierra baja, llena de yerba, por la cual se camina mal, por la humedad del suelo y espesura de yerba. Viene de debisetum, del verbo "dehesa," "que vale espesar y estrechar." Puede también ser del hebreo dese, herba, porque la dehesa no es otra cosa que campo de yerba. Una dehesa es un ecosistema seminatural donde ocurre cierta intervención humana. En las mercedes de Nuevo México esto era donde había pinos de piñón que eran apodados para quitar todos los brazos ya secos que le llamaban piñón blanco, que les gustaba a las amas de casa para cocinar y calentar, siendo que es leña seca. Este tipo de árbol también es el que produce la mejor almendra siendo que el árbol lo han cuidado mejor y es más fácil para juntar el piñón.

Una dehesa es un espacio donde se conserva más número de flora y fauna y tiene cierta importancia económica y social. No importa si es latín, árabe o hebreo es un sistema agroforestal con suelo pobre y clima áspero donde los humanos han intervenido para hacerlo productivo. Algunos estudiosos dicen que las dehesas no son ecológicamente sostenibles por la razón de tanta presión por los mercedarios. Hoy en día el departamento del manejo de tierras (BLM), la floresta (National Forest Service) y la oficina estatal de tierras manejan las dehesas, que a un tiempo eran parte de las mercedes. Son un tipo de tierras que antes se usaban para pasteo, pobladas de piñón, sabina y encino o roble. Una dehesa se puede entender mejor como un mosaico por sus varios usos. Es un sistema agroforestal que produce árboles, productos agrícolas y animales y es conocido como un sistema agrosilvopastoril.

En Nuevo México las dehesas son conocidas más como "llanos," o "llanuras" que viene siendo un campo llano, del latín PLANIS, A, UM, o cosa que no tiene tropiezo ninguno. Un lugar extendido sin altos ni bajos, y además de zacate está esparcido de chamiso, árboles de piñón, sabina y en lugares más altos, robles o encinas carrasqueñas.

A veces entre los montes y dehesas, especialmente donde hay mesas, existen también lo que se conoce como chorreras, es decir cuando cae mucha agua o hay nieve que derrite, corren los arroyitos y caen en forma de chorreras en rumbo del río Grande. Aquí también hay tetillas y lomitas, que parecen lomos muy suavecitos cubriendo el paisaje.

Los montes detrás de las dehesas a veces tienen cejas, que es la parte superior o cumbre del monte o sierra. Una ceja es como un borde de un bosque, que a distancia aparece como banda o faja de vegetación elevada. Aquí también hay colinas (Del lat. collīna, t. f. de collīnus, del collado), que son una elevación natural de terreno, menor que una montaña.

En Nuevo México a estas colinas las conocemos más como lomas o lomitas (De lomo), altura pequeña y prolongada. Además existen cerros y cerrillos (Del lat. cirrus, copo), elevación de tierra aislada y de menor altura que el monte o la montaña y tetillas, hinchazones en forma de una teta, que aparecen en los llanos o entre mesas.

\subsection{Solares}

Solar de la palabra suelo, que es echar suelos. Suelo donde se edifica casa. Un solar mide 50 
por 50 varas (o 137.5 pies por 137.5 pies) y es una porción de terreno donde se ha edificado o que se destina a edificar. En el Nuevo México los solares todos estaban ubicados arriba de la faja de la acequia, era el espacio entre la acequia y el ejido. Las casas en las mercedes, las que están lejos de una plaza o plazuela, arriba de la suerte y atrás del bordo de la acequia se construían en la forma de un $\mathrm{L}-\mathrm{o} \mathrm{U}$, y a veces se le iban añadiendo cuartos conforme crecía la familia con los cuartos en forma de chorro o largas. Además de la casa, la solera también llevaba la despensa, sótano, y a veces la leña, gallinero y trochil.

Además, adelante de la casa en el patio había unas terrazas pequeñas, en forma de una erita, conocidas como azoteas, donde las mujeres sembraban sus remedios o flores. Las plazas o plazuelas también eran en la forma de solares, o manzanas, donde la plaza era compuesta de varios solares en la forma de un rectángulo con la iglesia en un lugar central, luego rodeada de casas para hacer como un fuerte para la protección de los indígenas, especialmente de los comanches y apaches que seguido llegaban a la plazuela del Embudo y la gente tenía que meter todos sus animales adentro para que no se los robaran.

\section{Sistema de Acequia}

Luego abajo la plaza corre la acequia, en la forma de una faja que hace zig zag como una culebra, y abajo van las suertes. Si usa uno el cuerpo humano como modelo, la cabeza representa la cumbre de la sierra (por eso se le dice a alguien como yo que tiene el cabello blanco, "ya llego la nieve a la sierra o la Jicarita"), donde los brazos extendidos son parte de la cordillera y el pecho viene siendo los montes, luego el estómago la dehesa y la cintura (faja) representa la acequia, y las piernas son las suertes, con los cuadriles los altitos, el muslo de la pierna la jolla, luego las rodilla el banco que separa la jolla de la vega (la canilla) y los pies son la ciénaga y los dedos representan el bosque o por donde va el río; ahí están los esteros y resumideros. Así como una faja no se la puede poner uno ni muy arriba ni muy bajita, igual la acequia, ella dicta por donde tiene que ir para que corra el agua bien.

El siguiente poema anónimo nos recuerda lo que es una acequia:

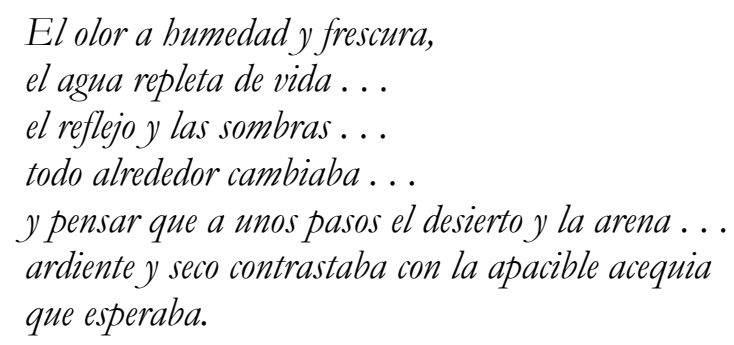

Estos versos definen también cómo una acequia sirve de faja para separar lo regado de la dehesa, cuando nos recuerda "y pensar que a unos pasos el desierto y arena," mientras "el agua repleta de vida ... todo alrededor cambiaba."

\subsection{Acequia Madre}

Y esta faja que llamamos Acequia Madre, que es como una culebra que hace zig zag por el pie de la mesa, o colina, por donde corre el agua como una lengua sedienta, que cuando primero echan el agua en la acequia la comunidad le llama "puntera." Se le llama así porque va recogiendo toda la basura que ha quedado en la acequia cuando se saca o se limpia en la primavera. Además, sirve para remojar los bordos y llenar abrevaderos. Pero para 
mejor comprender la acequia madre, pues empezamos en la cumbre de la sierra, que como dije es la hielera que guarda la nieve en forma de hielo para después soltarla como se ve derritiendo. El río entonces pasa por los montes, atraviesa cañadas, veredas y arroyos hasta que llega al plano de la dehesa y como el cuerpo humano que lleva la sangre por las venas o vetas, venas capilares, arterias, así va el agua.

Antes que el agua del río sea desviada para la acequia madre, antes de construirse el canal o zanja, tiene que hallarse un lugar donde se puede tomar el agua que se conoce como la "toma." Todo es que se identifica la toma del agua, lo primero que hace la gente o los futuros parciantes de la acequia es identificar donde existen veneros, venitas, ojitos o manantiales para que si llegan sequías como ha sucedido haya agua, aunque sea poca, para la acequia. Otra cosa muy importante, esta faja (la acequia madre) tiene que abarcar toda la tierra que sea posible, como dice el dicho, "el que mucho abarca poco aprieta," así sucede con las tierras marginadas que apenas alcanza a regar la acequia. La acequia de donde yo soy parciante, la acequia Junta y Ciénaga y ahora sirvo de comisionado y antes de mayordomo por cinco años, tiene bastantes venitas y veneros que aunque en tiempos de sequía, siempre está la acequia llena de agua. Aunque sea la última acequia en el río Embudo, a nosotros nunca nos falta el agua por la razón que tenemos muchos ojitos, venas y veneros de agua que nos han dicho vienen desde arriba de las sierras de Truchas, de donde nace la cuenca. Viene en forma de agua subterránea, que luego brota cuando llega el río. Esto más de todo enseña cómo está todo, desde la cabeza a los pies conectado como el cuerpo humano.

Una acequia y su servidumbre, que no ha cambiado mucho hoy día, según las Siete Partidas, dice, "la cual servidumbre tendrá dos tantos de ancho de la medida que tenga el alcabús (cauce), o cuatro pasos de Salomón, medidos a cada banda de la acequia, de la cual servidumbre, ninguna persona podría adueñarse por ser propiedad de la comunidad." Pues qué es un paso de Salomón, me costó mucho hallar, pero por fin lo encontré en un libro, "Riegos de la Nueva Vizcaya," del ingeniero Víctor Mendoza Magallanes, cuando me regaló este libro en una visita a Nuevo México. Pues un paso de Salomón viene siendo una vara y dos tercios, o sea 1.36 metros, esto según una ordenanza del virrey don Álvaro Manríquez en el 1589, cita Magallanes.

\subsection{La toma y la presa o azud y los desagües}

Identificando la toma, el siguiente quehacer es construir una presa o azud para desviar el agua del río a la acequia madre. Siguiendo la estructura de la acequia desde la presa hasta el último desagüe, que en el caso de la acequia nuestra corre por 2.5 millas hasta que cae al río Grande. De la presa a la compuerta mayor, tenemos dos desagües, esto para poder controlar mejor el agua que entra a la acequia madre. Uno como a 15 yardas de la toma y el otro antes de entrar a la compuerta principal. A cien yardas de la compuerta principal, que controla el agua que entra a la acequia, está el tercer desagüe. De ahí cruza la acequia el camino principal (camino estatal 75) y como por 50 yardas va por alcantarilla o como decimos nosotros caño por abajo de la tierra. Antes que pavimentaron el camino en el 1948, la acequia iba por un túnel de piedra, y por eso ahí le decían "el tunelito." También se le dice ahí "las pasaditas," y el nombre antiguo era la Angostura, siendo que es muy angosto del barranco de piedra al río. Antes solo era una vereda. De ahí corre la acequia como otras 50 yardas, luego cruza el camino otra vez y corre otras 50 yardas hasta el cuarto desagüe en el llamado arroyo de los Alamitos que baja al oriente de la mesita, que cruza por debajo el camino y la acequia derecho al río Embudo. De ahí corre la acequia otras cien yardas al oriente del camino rumbo al norte antes de cruzar otra vez el camino y de 
aquí se va como culebra atrincada a la mesita hasta que llega a la primera suerte. Esta es la primera granja y es como de cuatro hectáreas. Esta propiedad tiene dos regaderas o compuertas para regar y es compuesta de una terraza delgada que es un banquito llamado altito. Por ser que casi nunca pega el sol aquí durante el invierno por estar en el sombrillo de la mesita, el sacerdote que vivía aquí antes, que vino de Alemania en 1928 y tenía tres mujeres, le puso la oscurana porque en el invierno el sol se mete como a las tres de la tarde. Después sigue el terreno de un primo y como el anterior es de diez acres y también tiene dos regaderas. Esta parte se conoce como la Junta, como en la acequia Junta y Ciénaga. Luego hay tres terrenos como de cuatro acres, dos de 2.5 y uno de 1.5 acres, por un total de 38 acres en la tabla conocida como la Junta, con 8 parciantes. Aquí en este arroyo - el Jacinto, por el color de sus piedras - está otro desagüe, el quinto y este se usa más para cuando corren los arroyitos del norte de la mesita. Entonces usamos este desagüe para limpiar la acequia de la arena que baja.

\subsection{Acequia Junta y Ciénaga; secundarias y linderos}

La Junta y la Ciénaga están separadas por el arroyo Jacinto, y los terrenitos aquí son mucho más medianos, como 42 acres y 28 parciantes. La mayoría de los parciantes tienen de medio acre, un acre a dos y tres acres. El último desagüe es el que lleva al agua al río Grande. Antes estaba la acequia de la Nasa que empezaba donde terminaba nuestra acequia pero ellos solo tenían el "sobrante" de nuestra acequia. En la acequia de nosotros tenemos tres acequias secundarias, o linderos. El primero es el que pasa por mi propiedad y demarca la línea de la propiedad de dos vecinos hasta que llega a mi terreno y de ahí va en forma de cabecera/lindero por toda mi propiedad hasta que cruza el camino 68, que es la carretera principal entre Santa Fe y Taos. Antes del '48, cuando el camino iba por otro lado atrincado al río Grande y cerca de la Junta, cruzaba el río Embudo ahí en rumbo del Rincón, todas estas tierras eran de mi abuelo Tomás Archuleta, y antes de mi bisabuela Ramona Archuleta que estaba casada con Francisco Martín, que tenía mucho terreno. Ella se casó con él cuando tenía veinte años y él sesenta años y duraron casados diez años antes que él muriera. De ahí seguía el camino hacia Taos luego en los Barrancos Blancos agarraba otro brazo a la derecha en rumbo de la Plaza de Embudo de Nuestro Señor San Antonio, hoy día Dixon. Hoy este se conoce como camino estatal número 75 y es el que va a un lado de la acequia Junta y Ciénaga. El otro lindero empieza antes de cruzar el arroyo Jacinto, y corre al lado poniente de dicho arroyo hasta que cruza el camino luego va al lado de la tetilla de la Ciénaga, y riega la propiedad de siete familias y el último lindero esta todo es que la acequia vuelve a cruzar el camino y va por la propiedad de tres parciantes y riega otras tres propiedades al norte del arroyo Jacinto. Aquí llega el arroyo a fin siendo que vacía sus aguas en el río Grande.

Donde empieza la acequia Junta y Ciénaga en la Angostura, ahí es el desagüe de las dos acequias más viejas en la merced del Embudo, la acequia de la Plaza y la Acequia del Llano, que datan a los 1725 o poco después. La acequia de la Plaza empieza en la boca del arroyo de Lorenzo a al poniente del Montecito, y la del Llano empieza como una milla más arriba todavía en el Montecito y es la más larga como de cinco millas. Esta va atrincada a la colimas cerca de los camposantos y el ejido, mientras que la de la Plaza va abajo de la terraza que es como un bancal abajo de la iglesia católica, donde está la plaza antigua del Embudo.

Las cabeceras corren a lo largo de la acequia madre y de ahí se divide el agua para regar las suertes por surcos, conocidos como carreritas y de ahí se dividen en brazos y por fin ramos para regar las últimas esquina del terreno. El agua se divide con un tapanco, una palabra 
del náhuatl y de ahí estos surcos llevan el agua a las melgas (de mielgas), que se dividen en eras, parecidas a lo que los indígenas de Zuni llaman "waffle gardens," o las eras afghanis, que existen hasta en la ciudad de Chihuahua en México. Y el mejor modo para llevar el agua para que se consuma (penetre) y no se pierda el agua es por hilitos de agua. Recuerden que el agua es muy pesada y si echan mucha agua la tierra se aplana y el agua nomás corre pero no penetra como debe. Mi papa decía que una mata pide agua y es verdad, si la riegan de más no va a crecer y se va hacer amarilla.

Los linderos, a veces también son conocidas como acequias menores o secundarias corren a lo largo de un terreno, de la acequia al río. Antes cuando no había cercos el lindero servía para dividir una propiedad de un parciante del otro. Los linderos también sirven como desagües para las escurriduras que van a salir al río.

Las sangrías a veces se usan igual a la palabra lindero, pero según Gabriel Alonso de Herrera una sangría se usaba para secar una ciénaga para sembrar. Este palabra viene del concepto de cuando uno se machaca un dedo o la mano que se hace una llega de sangre y el único modo de aliviar el dolor es "sangrar" la herida, que corra la sangre que está atrapada, y es el mismo concepto con terreno que tiene mucha agua, se hace una acequiecita o "sangría" para quitar el agua.

El repartimiento es del modo que se reparte el agua durante tiempos de escasez. En el Embudo las cuatro acequias grandes de arriba agarran el agua por tres días, mientras las cuatro de abajo por cuatro días. Las únicas dos acequias que no participan en el repartimiento son la acequia Junta y Ciénaga y la del Rincón, las últimas dos en el tronco del río Embudo; como dije, por los ojitos y veneros no nos falta el agua. El agua se parte primero por acequia, luego dentro de cada acequia, por peones. En el valle del Embudo todas las acequias dividen el agua por peones. En la acequia de nosotros si un parciante tiene de un acre o menos, entonces tiene un cuarto de peón. Si tiene dos acres o menos tiene medio peón; tres acres o menos (yo tengo 2.5 acres o una hectárea) tres-cuartos de peón, cuatro acres, un peón. Los dos parciantes que riegan 10 acres tienen 2.5 peones.

Del modo que repartimos el agua, si el parciante desea regar de las cinco de la mañana a las cinco de la tarde (doce horas) entonces pide el agua al mayordomo. Si tiene un cuarto de peón agarra tres horas de riego; medio peón seis horas; tres cuartos de peón nueve horas y por cada peón 12 horas. Luego de las cinco de la tarde a las ocho de la tarde pueden usar el agua para los jardines; los de las Junta les toca de lunes a miércoles, los de la Ciénaga de jueves a sábado y los domingos cualquier puede usar el agua sin pedirla al mayordomo. Y de las ocho de la tarde a las cinco de la mañana la pueden usar sin pedírsela al mayordomo para regar huertos frutales, alfalfas o pasteo.

Todas las acequias están manejadas por una comisión de tres personas, el presidente, secretario y el tesorero y son los que hacen las decisiones para manejar la acequia, mientras el que maneja el agua de la acequia diariamente es el mayordomo.

El surco (y otras medidas antiguas) tiene dos contenidos, 1) es una medida antigua de agua, que era la cantidad de agua que cabe por el buje (hoyo) en una carreta antigua, que es como de seis pulgadas y 2) también es una carrerita que lleva agua (un surco) cuando se siembra. De las medidas antiguas solo usamos surco, en la memoria los de antes recordaban lo que era un buey de agua y en el Valle Allende en el sur de Chihuahua todavía riegan por naranjas. Jacinta Palerm y el señor Magallanes nos dicen que un buey de agua es el volumen que suponía pasar por entre las patas de un buey. Un buey viene siendo entonces una vara 
cuadrada o 725 litros de agua por segundo; 48 surcos hacen un buey, tres naranjas hacen un surco, ocho limones una naranja y 18 pajas un limón.

\section{Las Suertes}

En Nuevo México, en las tierras de mercedes, las suertes miden 200 varas castellanas por 400 varas de largas, que son aproximadamente 12.5 acres o cinco hectáreas. A una suerte se le daba un día de 24 horas para regar, y a la mayoría de los pobladores se le daba hasta tres suertes. Hoy en día estas suertes se han dividido en pedazos más medianos que les llaman tiras y en el sur de Colorado se les llaman extensiones. Las tierras de cultivo se conocían por tres términos, 1) tierras de pan coger, de humedad o trasporo, 2) tierras de pan sembrar, de riego y 3) tierras de pan llevar, de secano o temporales. En documentos antiguos de la merced del Embudo aparecen estos términos.

Los altitos son terrazas en forma de bancos y van de la cabecera hasta la siguiente terraza; aquí se plantan los buertos de árboles frutales en forma de tablas. Este es el mejor lugar para los árboles frutales porque están más protegidos del frío y del hielo que a veces llega hasta mediados de mayo. Antes, me han contado, cuando corrían las acequias todo el año como su agua servía para la casa y los abrevaderos, ahí por enero soltaban el agua por parejo, o a manta, para regar los árboles de albaricoque o durazno y la dejaban correr hasta que se hacía una plancha de hielo. Luego para que durara más le echaban aserrín arriba y esto protegía al hielo para que no se derritiera y no reventara la flor del árbol tan temprano. Así, como los capullos se retrasaban más en reventar, había más fruta que hoy día. Esta era una estrategia para que hubiera fruta.

Abajo de los altitos venían los bancales conocidos como jollas, donde se sembraban las buertas de chile, o las milpas donde iban también las calabazas y frijol. Se les llamaban jollas porque eran las más ricas que existían y se conocían como tierras de pan sembrar. Estas tres se sembraban como hermanas, donde el frijol se enredaba en la mata de maíz y la calabaza le hacía sombra a los pies del maíz y así preservaba la humedad y no se tenía que regar tanto. Tanto el chile como el maíz se siembra en melgas, que después se divide en lo que le llamaban eras.

La otra terraza en la suerte separa la jollas de las vegas. En las vegas de Nuevo México no se siembra como en las vegas de Andalucía, siendo que las vegas son más para crecer zacate para los animales domésticos, sean las vacas de ordeña, borregas y cabras. Estas a veces si pasan cerca el río tienen unas terrazas en formas de ancones, que se forman como remolino donde hace vuelta el río. La última terraza es la de la ciénaga, donde también se forma un tipo de terrazas conocidas como ancones. El único modo que se puede utilizar una ciénaga para sembrar es si se "sangra" con una acequiecita llamada sangría. Cuando estas tierras se siembran se llaman tierras de pan coger, de humedad o trasporo. Luego por fin llegamos al bosque por donde corre el río y sus esteros y resumideros.

\section{Aldeas de la cuenca baja del embudo de Picurís y sus acequias}

Para comprender mejor las acequias dentro de la merced del Embudo, imaginen cada acequia como una terraza singular, y dentro de cada una de estas terrazas existen diferentes tipos de terrazas más medianas, como apunte ahorita, altitos, jollas, vegas, ciénagas y bosques con sus esteros y resumideros. 
Todas las aldeas dentro de la merced tienen nombres relacionados a la tierra que les dio su nombre, con la excepción hoy en día de la Plazuela del Embudo de Nuestro Señor San Antonio, que en el 1900 con la casa de correos establecida por los Estados Unidos le cambiaron el nombre a Dixon, en honor del primer maestro de inglés, que llegó aquí como desertor del ejército durante la Guerra Civil. Cuando iban a nombre la estafeta, la señora estafetera le preguntó al señor Collins Dixon, "¿Cuál será un buen nombre para la estafeta?" a lo que él respondió, "Dixon," y así se quedó. Luego para no perder el nombre Embudo, cuando pusieron una estafeta nueva al poniente del arroyo Jacinto, entre la Junta y la Ciénaga, nombraron la estafeta Embudo, que hoy en día sirve a esas comunidades, además de la Nasa, el Rincón, la Bolsa, la Rinconada y hoy hasta la Cieneguilla, nombrada Pilar. Además están dos lugarcitos muy pequeños al norte del río Grande, el Vado entre la Rinconada y la Bolsa, que a uno tiempo tenía una acequiecita y luego más abajo, al poniente de la Cañada de los Comanches está el Bosquecito de los Córdovas. Las comunidades las vamos a ver del oriente al poniente, empezando donde sale el río Embudo de su viaje de las Sangre de Cristo hacia el golfo de México. A la salida de la boca del cañón, o la garganta, la primera aldea se llama Cañoncito, siendo que está en forma de cañón e incluye la acequia Martínez-Arellano que riega como 30 acres al lado norte del río Embudo con siete parciantes. Al sur del río empieza la acequia de la Sancochada que riega aproximadamente 40 acres y tiene 25 parciantes. La otra acequia que empieza en el Cañoncito, al poniente del arroyo del Pinorreal y el arroyito de Agua y termina cerca el Arroyo Lorenzo en el Montecito es la acequia del Medio con 150 acres y 45 parciantes. Directamente al otro lado del río está la acequia de los Duranes, otra acequia que riega como 35 acres y 18 parciantes. La acequia del Medio riega como 150 acres en el Cañoncito y Montecito. En lo que se conoce como el Montecito existen cuatro acequias y dos arroyos; en el norte está la del Apodaca y la del Bosque y en el sur la acequia del Llano, la más larga de cinco millas y riega cerca de 200 acres. Esta es la más vieja, data como al año 1725 y también la acequia de la Plaza, que riega la tierra abajo de la plaza hasta el rio.

$\mathrm{Al}$ otro lado del Montecito, al lado norte del río Embudo está la aldea de la Apodaca en un pedazo que compró el señor Nicolás Apodaca en el 1751 de la familia Martín. Esta comunidad se riega parte por la acequia de los Duranes, pero la mayoría por la acequia de la Apodaca que tiene 37 parciantes y como 80 acres, cuyo desagüe al río está al otro lado del camino 75 al principio de la comunidad del Bosque de los Ángeles. La acequia del Bosque riega como 80 acres y tiene 35 parciantes que va hasta donde llega al desagüe en el arroyo del Pino, también conocido como el arroyo de Vaca en la otra banda del lado norte. De este lado hay dos arroyos secos grandes, el arroyo del Plomo conocido también como el arroyo de la Apodaca y el arroyo del Bosque. Al otro lado del río por donde pasa el Camino Real de Tierra Adentro hacia Taos y Picuris está la Plaza del Embudo de Nuestro Señor San Antonio, hoy día Dixon. Esta lonja de terreno entre el Arroyo de Lorenzo y la Cañada del Embudo, hoy día el arroyo de la Mina, es lo que viene siendo Dixon. Hay varios arroyos secos entre estos dos más grandes que parecen más cañadas, está el arroyo del Tuerto, luego sigue el arroyo de la Plazita, el arroyo de los Cuates y el arroyo de la Plaza. Esta lonja la más grande del valle del Embudo se riega con la acequia del Llano y la acequia de la Plaza, una riega como 200 acres con 127 parciantes y la otra como 165 con acres y 70 parciantes y son las dos más antiguas, desde el principio de la merced en el 1725. Estas tienen el mismo desagüe en la Angostura, antes que se empiece la acequia Junta y Ciénaga. Todas las comunidades mencionadas reciben su correo en Dixon y por eso los recién llegados crean que todo se llama Dixon pero no es así como les conté ahora. Para los locales todos usamos el nombre histórico para los pueblitos igual que para los arroyos, otra cosa que se está acabando, o le han puesto nombres dados por los gringos, por 
ejemplo el arroyo de la Mina lo nombraron por un artista que ahora vive a la entrada llamado Jim Gilbert. Le dicen Jim Gilbert's arroyo, mientras entre nosotros nunca usamos los nombres de persona o muy a lo lejos para nombre el paisaje.

Ahora vamos a conocer a las comunidades que reciben su correo en la estafeta del Embudo. Donde vivo yo se llama la Junta siendo que ahí es donde se junta el río Embudo con el río Grande. La Junta y la Ciénaga se riegan con una acequia del mismo nombre y riega como 80 acres y tiene 37 parciantes. Al otro lado del río de la junta queda un rinconcito donde viven solo cuatro familias que se llama Rincón. Esta se riega con una acequia del mismo nombre y riegan como doce acres con siete parciantes, la más mediana de todas las acequias de comunidad. Continuando hacia el poniente, al otro lado del arroyo Jacinto queda la Ciénaga, ésta queda como en un poso atrincado al sur del río Grande y viven como 20 familias, la mayoría de ellos Griegos y Archuletas. Aquí abaja la Cañada de los Comanches, al norte del río Grande en frente de la Ciénaga y poco más al poniente abajan las Chorreras de la mesa negra. Luego al otro lado del río Grande está un lugarcito de cuatro familias llamado el Bosquecito de los Córdobas. Aquí también abandonaron su acequia tradicional y ahora riegan con bomba. Como dos millas y medio al poniente está la Nasa donde viven como cinco familias, todos parientes y es aquí donde llego el tren conocido como el Chile Line el día de Santa Rosa en el 1881, y se celebró la llegada con una fiesta, y hasta el día se celebra la fiesta pero ahora se hace en Dixon. La Nasa se regaba antes con las escurriduras de la acequia Junta y Ciénaga, pero hace como diez años que la abandonaron y ahora riegan con bomba. Aquí baja un arroyo seco de la mesita llamado arroyo de la Jolla.

Luego al noreste de la Junta llegamos al lugar conocido como los Barrancos Blancos, y atrás de aquí está un poso que parece un bolsón, conocido como Bolsa. Aquí viven casi puros gabachos, solo una familia de raza quedó y al otro lado del río Grande está en lugarcito que se llama el Vado. De la Bolsa continuando al noreste rumbo a Taos, está la comunidad de la Rinconada, que es un rincón más grande donde se da mucha fruta de toda clase y aquí también la mayoría son gabachos y aquí está situado la clínica de salud del lugar. Este lugar se riega con una acequia muy antigua, que algunos dicen data a los 1680s, pero yo personalmente no he visto dicha documentación. Ahora su acequia es una moderna sin presa y todo corre con bomba de gasolina, en lugar de la gravedad como antes. Igual con la acequia del Vado, la Bolsa y del Bosquecito de los Córdobas. Al noreste de la Rinconada está un lugarcito en el banco del río Grande que le llaman el Carrizalito.

\section{Conclusiones}

Al ver el marco completo, del punto de vista como el cuerpo humano, las acequias no están funcionando muy bien. No solo tienen el problema de la erosión del paisaje, pero también la erosión de la lengua cual lleva nuestra sabiduría ambiental. Una merced se divide en tres partes, 1) los ejidos, 2) la faja que divide lo común de la propiedad privada, llamada la acequia y 3) las suertes que son de regadío. Y lo que une a todas es la lengua. La infraestructura también ocupa mucho trabajo, al tanto de remover tantas especies invasoras.

\section{Agradecimientos}

Este trabajo es más un reflejo personal de arriba de 40 años queriendo conocer y entender 
el lugar que vivo, y en cuyo lugar están las raíces de mi familia desde el 1725. Muchos de estos conceptos vinieron de mi padre y de amigos del que se volvieron mis amigos: Pablo Romero, Maximilio Sánchez, Abel Pineda, Andrés Martínez de Taos, Cleofes Vigil de San Cristóbal y otros.

Los siguientes textos históricos fueron consultados: 1) Las Siete Partidas del 1256, 2) las Ordenanzas de Descubrimiento, Nueva Población y Pacificación de las Indias, de 1573 , 3) La Recopilación de las Leyes de los Reynos de Indias del 1681, y 4) El Plan de Pitic del 1783, además del trabajo de la Dra. Palerm, Jacinta y Chariz, Carlos, "Medidas antiguas de agua novohispanas y mexicanas," CIESAS, Vol., 2011, 278p. y de Mendoza Magallanes, Víctor (1989) "Riegos de la Nueva Vižaya," Talleres Gráficos del Gobierno, Chihuahua, Chih. 